\title{
BMJ Open COVID-19 risk perceptions of social interaction and essential activities and inequity in the USA: results from a nationally representative survey
}

Daniel J Erchick (D) , ${ }^{1}$ Alexander J Zapf, ${ }^{1}$ Prativa Baral, ${ }^{1}$ Jeffrey Edwards, ${ }^{1}$ Shruti H Mehta, ${ }^{2}$ Sunil S Solomon, ${ }^{2,3}$ Dustin G Gibson,, ${ }^{1,4}$ Smisha Agarwal, ${ }^{1,4}$ Alain B Labrique $e^{1,2,4}$

To cite: Erchick DJ, Zapf AJ, Baral P, et al. COVID-19 risk perceptions of social interaction and essential activities and inequity in the USA: results from a nationally representative survey. BMJ Open 2022;12:e051882. doi:10.1136/ bmjopen-2021-051882

- Prepublication history and additional supplemental material for this paper are available online. To view these files, please visit the journal online (http://dx.doi.org/10.1136/ bmjopen-2021-051882).

Received 30 March 2021 Accepted 20 January 2022

Check for updates

(C) Author(s) (or their employer(s)) 2022. Re-use permitted under CC BY-NC. No commercial re-use. See rights and permissions. Published by BMJ.

For numbered affiliations see end of article.

Correspondence to Dr Daniel J Erchick; derchick@jhu.edu

\section{ABSTRACT}

Introduction SARS-CoV-2 has disproportionately affected disadvantaged communities across the USA. Risk perceptions for social interactions and essential activities during the COVID-19 pandemic may vary by sociodemographic factors.

Methods We conducted a nationally representative online survey of 1592 adults in the USA to understand risk perceptions related to transmission of COVID-19 for social (eg, visiting friends) and essential activities (eg, medical visits or returning to work). We assessed relationships for activities using bivariate comparisons and multivariable logistic regression modelling, between responses of safe and unsafe, and participant characteristics. Data were collected and analysed in 2020.

Results Among 1592 participants, risk perceptions of unsafe for 13 activities ranged from $29.2 \%$ to $73.5 \%$. Large gatherings, indoor dining and visits with elderly relatives had the highest proportion of unsafe responses $(>58 \%)$, while activities outdoor, accessing healthcare and going to the grocery store had the lowest $(<36 \%)$. Older respondents were more likely to view social gatherings and indoor activities as unsafe but less likely for other activities, such as going to the grocery store and accessing healthcare. Compared with white/Caucasian respondents, black/African-American and Hispanic/Latino respondents were more likely to view activities such as dining and visiting friends outdoor as unsafe. Generally, men versus women, Republicans versus Democrats and independents, and individuals with higher versus lower income were more likely to view activities as safe.

Conclusion Evidence-based interventions should be tailored to sociodemographic differences in risk perception, access to information and health behaviours when implementing efforts to control the COVID-19 pandemic.

\section{INTRODUCTION}

As of November 2021, SARS-CoV-2, the virus that causes COVID-19, has infected more than 47 million people and contributed to over 767000 deaths in the USA. ${ }^{1}$ The negative health and social consequences of the
Strengths and limitations of this study

- Our study had a sample of sufficient size to explore associations by race/ethnicity and other important participant characteristics.

- We provided insights into perceived risks for specific activities during a later stage of the COVID-19 pandemic than previous studies.

- Our findings suggest the importance of socioeconomic differences, health disparities and structural racism for efforts to control the COVID-19 pandemic.

- Selection bias associated with online surveys is well established; for example, under-representing individuals who are older, without internet access, have lower income and have less formal education.

- Numbers of participants for some participant characteristics, including certain racial and ethnic minorities, were too small to provide sufficient statistical power for our analyses.

COVID-19 pandemic-including morbidity and mortality; decreased access to healthcare; and lost jobs and economic hardships-have not been experienced equally and instead have impacted certain communities in greater numbers and with increased severity. For example, COVID-19 related diagnoses, hospitalisations and deaths have disproportionately affected black communities ${ }^{2}$ and those in poverty, ${ }^{3}$ demonstrating the impact of structural racism and health disparities in disadvantaged populations. ${ }^{4}$

Numerous COVID-19 pandemic, tracking, mapping and monitoring tools have emerged, covering a wide array of indicators from testing capacity to daily case counts and deaths to policy interventions. ${ }^{56}$ While data collected from these trackers provide critical insights into the COVID-19 pandemic trajectory and public health response measures, they rarely address upstream sociobehavioural 
aspects, such as risk perceptions, knowledge and access to information, spread of misinformation, and agency and stigma. Yet access to information and health literacy vary by age, gender and race and other characteristics with important implications for risk perceptions, behaviours and health outcomes, including COVID-19 infection and mortality. ${ }^{7}$

Few studies have sought to estimate prevalence of risk perceptions related to social interaction or essential activities during the COVID-19 pandemic or explore associations between these perceptions and sociodemographic factors, including by age, race, income or education. ${ }^{89}$ Differences in risk perceptions could provide insights into the determinants of risk perception and health knowledge and subsequent behaviours related to the COVID-19 pandemic, while also helping to inform development of targeted communication campaigns and preventive interventions. ${ }^{1011}$

The National Pandemic Pulse is a US population representative, internet phone/computer survey designed to obtain data on preventive behaviours, risk perceptions, agency and stigma, and misinformation related to the ongoing COVID-19 pandemic across census regions. ${ }^{12}$ Our aim is to examine relationships between these issues and sociodemographic factors, especially age, race, income and education, to understand how systematic racism and inequity impact health and well-being in the context of the COVID-19 pandemic. Here we present findings from the first national Pandemic Pulse Survey to understand racial and sociodemographic differences in risk perceptions of social interaction and essential activities during the COVID-19 pandemic.

\section{METHODS}

\section{Study population}

We conducted a cross-sectional online survey of adults currently living in the USA ages 18 years and older from 1 to 7 September 2020. The sample was selected from an online panel to represent the US Census population using prespecified demographic quotas for age, gender, race, census region and income. Black/AfricanAmerican and Hispanic/Latino respondents were oversampled by approximately 385 individuals per group to increase power for analyses comparing risk perceptions by ethnicity/race groups. This sample allowed for detection of a $10 \%$ difference in proportions between white, black and Hispanic ethnicity/race groups assuming power of $80 \%$, type I error rate of 0.05 and a baseline prevalence of $40 \%-60 \%$. Dynata-a market research firm (https://www.dynata.com) that maintains a large first-party global data platform, including 62 million panellists with accompanying demographic information-selected a random sample from their database to match the US Census estimates. Dynata sent invitations by email to 16904 panellists matching the required demographic targets of the survey until each quota was filled. The survey response rate was $10.0 \%$, and completion rate among eligible respondents was $95.3 \%$. Survey responses were excluded for the following reasons: age less than 18 $(n=47)$, residence outside USA $(n=3)$, ethnicity/race for which sample quota was already filled $(n=171)$, refusal of consent $(n=72)$ and partial interview $(n=77)$. Security and data quality checks used included digital fingerprinting and spot-checking via third-party verification to confirm the identity of the respondents and prevent duplication. Participants received a small compensation for survey completion.

\section{Questionnaire}

A team of experts at Johns Hopkins Bloomberg School of Public Health collated COVID-19 questions from existing surveys and created new questions to address existing gaps in the literature. In a module on risk perception, the focus of this analysis, participants were presented with a series of thirteen activities related to social (eg, visiting friends or dining in restaurants) and essential (eg, medical visits or returning to work) activities and asked to respond to the question: how safe or unsafe do you think the following activities are in terms of your getting COVID-19 or giving it to someone else? (online supplemental figure $1)$. Allowed responses included extremely safe, somewhat safe, somewhat unsafe, extremely unsafe, unsure and prefer not to say. For the purpose of this analysis, we collapsed extremely and somewhat categories into perceptions of 'safe' and 'unsafe'.

\section{Statistical analysis}

All analyses were adjusted for the study design using survey weights for race by Census region generated using the 2010 US Census estimates. We presented a histogram of the prevalence of risk perceptions for the overall study population (responses of safe, unsafe and unsure) for each of the 13 activities. We assessed bivariate relationships between a three-level categorical (safe, unsafe and unsure) variable and participant characteristics for each activities. We reported the absolute per cent difference in perceptions between levels of participant characteristics variables and assessed statistical significance using Pearson's $\chi^{2}$ tests. We used multivariable logistic regression models to calculate unadjusted and adjusted ORs (OR and aOR) of perceiving each activity as unsafe versus safe and associated 95\% CIs (responses of unsure were excluded from regression analyses). Participant demographic and socioeconomic characteristics included in multivariable models were age, gender, race/ethnicity, education, income, census region and political affiliation. To assess differences in risk perceptions by age and race, we presented regression models overall for all participants and stratified by white/Caucasian, black/AfricanAmerican and Hispanic/Latino groups. Multivariable logistic regression models were also extended to include interaction terms for age and race and assessed for significance using Wald tests $(\mathrm{p}<0.05)$. Statistical analyses were conducted in Stata V.16.1 (StataCorp, College Station, Texas, USA). 


\section{RESULTS}

\section{Participant characteristics}

Complete responses from 1592 respondents were included in this analysis. Roughly half of respondents were less than 45 years old $(52.2 \%)$ and female $(49.5 \%)$ (weighted percentages; table 1). Participants were $60.0 \%$ white/Caucasian, $12.4 \%$ black/African-American and 18.4\% Hispanic/Latino. Risk perceptions of unsafe for the 13 activities ranged from $29.6 \%$ to $73.5 \%$ and unsure from $3.7 \%$ to $11.6 \%$ (figure 1). Large gatherings (of 10 , 100 and church), indoor dining and visits with elderly relatives had the highest proportion of unsafe responses $(>58 \%)$, while activities outdoor (dining, visiting friends), visiting the doctor or dentist and going to the grocery store had the lowest proportion $(<36 \%)$.

\section{Large gatherings and activities in public}

Perceptions of unsafe increased by $>15 \%$ from the lowest to highest age categories (18-24 to 65+ years) for gathering of 10, gathering of 100 and going to church (all $\mathrm{p}<0.001)$ but decreased by a similar amount for going to the grocery store $(p=0.015)$. Males were less likely than women to perceive these activities as unsafe, with significant differences $(\mathrm{p}<0.05)$, ranging from $-3.3 \%$ to $-7.4 \%$, except gathering of 10 . Perceptions differed by race only for gatherings of 10 , highest among Hispanic/ Latino $(67.5 \%)$ and Asian/Pacific Islander respondents $(67.1 \%) \quad(\mathrm{p}=0.011)$. Respondents with higher education were less likely to perceive gathering of 100 as unsafe $(\mathrm{p}=0.024)$. Perceptions of unsafe decreased with increasing income $(\mathrm{p}<0.05)$, with differences between $<\$ 20000$ and $\geq \$ 100000$ categories ranging from $-3.2 \%$ to $-10.2 \%$. Democrats and independents were more likely to perceive activities as unsafe for all variables compared with Republicans $(\mathrm{p}<0.001)$.

In multivariable models (figure 2, online supplemental table 1, online supplemental figure 2) perception of unsafe increased with age for gathering of $10(\mathrm{aOR}=1.24$ (95\% CI 1.14 to 1.35$)$ ), gathering of $100(\mathrm{aOR}=1.38(95 \%$ CI 1.25 to 1.52)) and going to church (aOR=1.18 (95\% CI 1.09 to 1.28) ) and decreased for going to the grocery store $(\mathrm{aOR}=0.89$ (95\% CI 0.82 to 0.96$)$ ). Men were less likely to perceive activities as unsafe. Across income groups, there was a significant decrease in perception of unsafe with increasing income for gathering of $10 \quad(\mathrm{aOR}=0.86$ (95\% CI 0.77 to 0.96$)$ ) and going to the grocery store $(\mathrm{aOR}=0.83$ (95\% CI 0.74 to 0.92$)$ ). Democrats and independents were more likely to report activities as unsafe relative to Republicans.

\section{Indoor and outdoor dining and visits with relatives}

Perceptions of unsafe increased between lowest and highest age categories (18-24 to $65+$ years) by $>10 \%$ for dining indoor $(\mathrm{p}<0.001)$ and visiting friends indoor $(\mathrm{p}=0.001)$, and decreased, ranging from $-3.1 \%$ to $-10.1 \%$, for visiting elderly relatives $(\mathrm{p}=0.039)$, visiting friends outdoor $(\mathrm{p}=0.001)$ and dining outdoor $(\mathrm{p}=0.006)$. Men compared with women were less likely to perceive

\begin{tabular}{|c|c|c|}
\hline Characteristic & $n=1592 \dagger$ & Percent‡ \\
\hline \multicolumn{3}{|l|}{ Age (years) } \\
\hline $18-24$ & 187 & 10.3 \\
\hline $25-34$ & 352 & 21.7 \\
\hline $35-44$ & 305 & 20.2 \\
\hline $45-54$ & 245 & 16.3 \\
\hline $55-64$ & 239 & 14.7 \\
\hline $65+$ & 264 & 16.8 \\
\hline \multicolumn{3}{|l|}{ Gender } \\
\hline Female & 800 & 49.5 \\
\hline Male & 786 & 50.5 \\
\hline Other & 1 & 0.0 \\
\hline \multicolumn{3}{|l|}{ Race } \\
\hline White/Caucasian & 685 & 60.0 \\
\hline Black/African-American & 410 & 12.4 \\
\hline Hispanic/Latino & 382 & 18.4 \\
\hline Asian/Pacific Islander & 61 & 5.8 \\
\hline American Indian/Alaska Native & 20 & 0.7 \\
\hline Other & 34 & 2.8 \\
\hline \multicolumn{3}{|l|}{ Education } \\
\hline High school or less & 345 & 20.2 \\
\hline Associate degree & 215 & 13.2 \\
\hline Some college (no degree) & 289 & 17.9 \\
\hline Bachelor's degree & 450 & 28.9 \\
\hline Graduate degree & 288 & 19.7 \\
\hline \multicolumn{3}{|l|}{ Income } \\
\hline$<\$ 20000$ & 273 & 16.3 \\
\hline$\$ 20000-<\$ 40000$ & 317 & 19.0 \\
\hline$\$ 40000-<\$ 70000$ & 416 & 26.9 \\
\hline$\$ 70000-<\$ 100000$ & 258 & 16.8 \\
\hline$\geq \$ 100000$ & 315 & 21.0 \\
\hline \multicolumn{3}{|l|}{ Lost job } \\
\hline No & 1008 & 65.3 \\
\hline Yes & 333 & 19.8 \\
\hline Retired & 234 & 14.9 \\
\hline \multicolumn{3}{|l|}{ Census region } \\
\hline Northeast & 312 & 17.1 \\
\hline Midwest & 347 & 20.8 \\
\hline South & 561 & 38.3 \\
\hline West & 372 & 23.9 \\
\hline \multicolumn{3}{|l|}{ Political party } \\
\hline Republican & 429 & 39.1 \\
\hline Democrat & 699 & 32.2 \\
\hline Independent & 371 & 25.2 \\
\hline Other & 52 & 3.5 \\
\hline
\end{tabular}

*Participant responses not listed in table include the following: 'other' and 'prefer not to say' categories (number, percentage adjusted for survey sample design): age: $n=0$; gender: refuse $(n=5,0.3 \%)$; race: $n=0$; education: refuse $(n=5,0.2 \%)$, income: refuse $(n=13,0.6 \%)$; lost job: refuse $(n=17,0.9 \%)$; census: $n=0$; and political affiliation: refuse $(n=41,2.1 \%)$.

†Actual numbers of individuals surveyed.

‡Overall population percentage adjusted for survey sample design by weighting for race by Census region. 


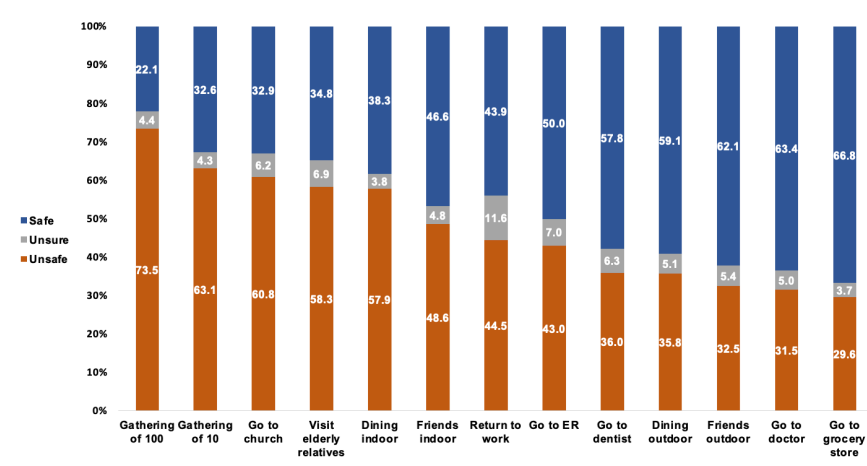

Figure 1 Participant risk perceptions for each activity. Percentages are the weighted estimates adjusted for race by Census region to match the overall US population. Extremely safe and somewhat safe and extremely unsafe and somewhat unsafe response categories were collapsed into safe and unsafe, respectively.

activities as unsafe, with significant differences $(\mathrm{p}<0.05)$, ranging from $-3.3 \%$ to $-10.3 \%$, except for visiting friends outdoor. Activities in this category varied by race, with white/Caucasian respondents generally less likely to perceive them as unsafe. Respondents with higher education were less likely to perceive dining outdoor as unsafe $(p=0.040)$. Perceptions of unsafe decreased with increasing income $(\mathrm{p}<0.05)$ for most of these activities, ranging from $-3.8 \%$ to $-11.8 \% \quad(<\$ 20000$ to $\geq \$ 100000$ categories), except for visiting friends indoor. Democrats and independents were more likely to report activities as unsafe relative to Republicans $(\mathrm{p}<0.001)$.

In multivariable models (figure 3), risk perception across age groups increased significantly for dining indoor $(\mathrm{aOR}=1.12$ (95\% CI 1.04 to 1.21$)$ ) and visiting

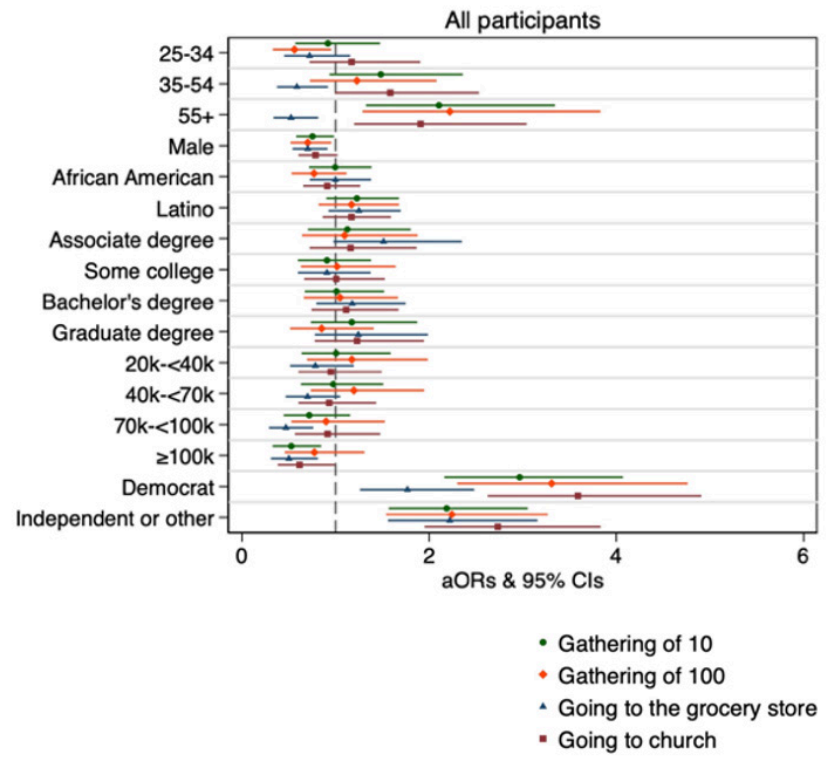

Figure 2 Adjusted ORs (aORs) of perceiving large gatherings and activities in public as unsafe for all participants. Reference groups are age: 18-24 years; gender: female; race: white/Caucasian; education: high school or less; income: <\$20 000; political party: Republican.

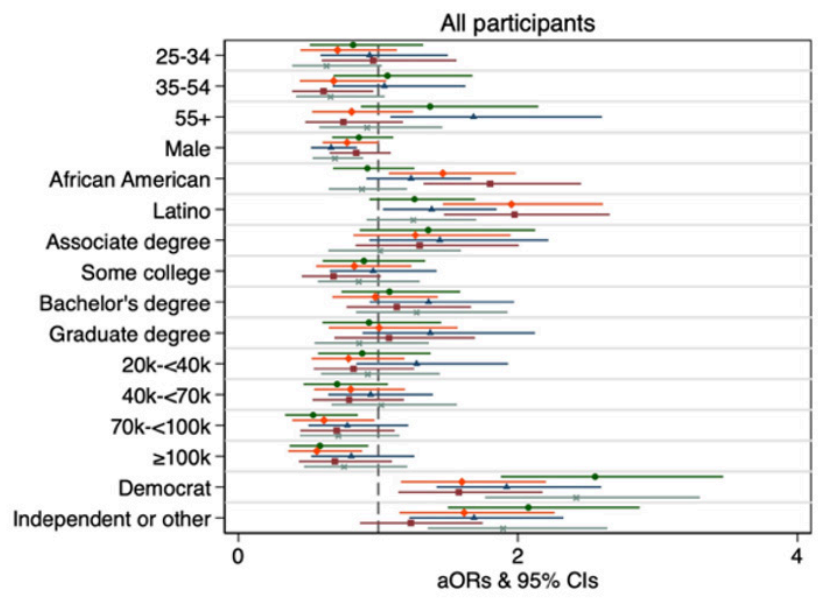

- Dining indoor

- Dining outdoor

- Visiting friends indoor

- Visiting friends outdoor

* Visiting elderly relative

Figure 3 Adjusted ORs and 95\% Cls of perceiving indoor and outdoor dining and visits with friends and relatives as unsafe for all participants. Reference groups are age: 18-24 years; gender: female; race: white/Caucasian; education: high school or less; income: $<\$ 20000$; political party: Republican.

friends indoor ( $\mathrm{aOR}=1.15$ (95\% CI 1.07 to 1.24$)$ ). Men relative to women had lower odds of viewing these activities as unsafe, but this was only significant for visiting friends indoor. There was a significant decreasing trend across income groups for dining indoor $(\mathrm{aOR}=0.87(95 \%$ CI 0.78 to 0.97$)$ ) and dining outdoor $(\mathrm{aOR}=0.87(95 \%$ CI 0.78 to 0.96 )) but not visiting friends in either setting. Compared with white/Caucasian respondents, black/ African-American and Hispanic/Latino respondents were more likely to view dining outdoor and visiting friends outdoor as unsafe. Democrats were more likely to view these activities as unsafe relative to Republicans. There was a statistically significant interaction between age and race for visiting an elderly relative $(\mathrm{p}=0.061)$ (online supplemental table 2). The change in odds of perceiving visiting an elderly relative as unsafe for each 10-year increase in age was non-significant among white/Caucasian respondents (aOR=0.99 (95\% CI 0.89 to 1.10$)$ ) and Hispanic/Latino respondents $(\mathrm{aOR}=1.11$ (95\% CI 0.96 to 1.29)) but significant among black/African-American respondents ( $\mathrm{aOR}=1.35$ (95\% CI 1.15 to 1.58$)$ ).

\section{Medical visits and returning to work}

Perceptions of unsafe decreased $(-16.2 \%$ and $-6.3 \%$, respectively) between the lowest and highest age categories $(18-24$ to $65+$ years) for doctor visits $(p<0.001)$ and going to the emergency room $(\mathrm{p}=0.006)$ and increased $(4.2 \%)$ for returning to work $(\mathrm{p}<0.001)$. Men were less likely than women to perceive these activities as unsafe, with significant differences $(\mathrm{p}<0.05)$ ranging from $-5.9 \%$ to $-10.5 \%$. Dentist visits were the only activity for which risk perception significantly differed by race $(\mathrm{p}<0.001)$. 
Respondents with lower education were more likely to respond 'unsure', with differences $(\mathrm{p}<0.05)$ between lowest and highest categories (high school or less to graduate degree) ranging from $-5.2 \%$ to $-6.9 \%$. Respondents with higher income were less likely to perceive these activities as unsafe with a range of difference between the lowest and highest categories $(<\$ 20000$ to $\geq \$ 100000)$ of $-4.3 \%$ and $-12.5 \% \quad(\mathrm{p}<0.05)$. Democrats and independents were more likely to report activities as unsafe relative to Republicans $(\mathrm{p}<0.001)$.

In multivariable models (online supplemental figure 3), a risk perception of unsafe across age groups decreased significantly for going to the doctor $(\mathrm{aOR}=0.84$ (95\% CI 0.78 to 0.91$)$ ) and emergency room (aOR=0.90 (95\% CI 0.84 to 0.97$)$ ). Males were less likely to view going to the doctor, emergency room and returning to work as unsafe. Compared with white/Caucasian respondents, Hispanic/ Latino respondents were more likely to view going to the dentist or emergency room as unsafe. Respondents with higher income were less likely to view these activities as unsafe; trends across income groups were statistically significant for going to the doctor $(\mathrm{aOR}=0.84$ (95\% CI 0.75 to 0.94$)$ ), dentist ( $\mathrm{aOR}=0.87$ (95\% CI 0.78 to 0.97$)$ ) and emergency room ( $\mathrm{aOR}=0.86$ (95\% CI 0.78 to 0.96$)$ ). Democrats and independents were more likely to view activities as unsafe. There was a statistically significant interaction between age and race for returning to work $(\mathrm{p}=0.039)$. The change in odds of perceiving returning to work as unsafe for each 10-year increase in age was smallest for white/Caucasian respondents $(\mathrm{aOR}=1.13$ (95\% CI 1.00 to 1.27$)$ ) followed by Hispanic/Latino respondents $(\mathrm{aOR}=1.21$ (95\% CI 1.03 to 1.42$)$ ) and black/African-American respondents $\quad(\mathrm{aOR}=1.31 \quad(95 \%$ CI 1.12 to 1.52 )).

\section{Census region}

Differences between census regions in bivariate comparisons included higher proportions of respondents considering activities as unsafe in the west versus north (gathering of 10, gathering of 100, grocery store, church and dentist) and south versus north (dining indoor). Census region was only predictive of risk perception in multivariable models for three activities (dining indoor: Midwest vs Northeast: aOR=0.66 (95\% CI 0.44 to 0.98 ); visiting friends indoor: Midwest vs Northeast: $\mathrm{aOR}=0.68$ (95\% CI 0.46 to 1.00 ); and dining outdoor: South vs Northeast aOR=1.44 (95\% CI 1.01 to 2.06$)$ ).

\section{DISCUSSION}

We conducted a nationally representative survey of the US population to understand risk perceptions related to transmission of COVID-19 for social interaction and essential activities. Overall, risk perceptions ranged widely but were higher for activities that have been shown to present increased risk for COVID-19 infection, particularly large gatherings and indoor activities, suggesting effective information dissemination to the public regarding COVID-19 risk factors. ${ }^{13}$ Risk perceptions for age and race varied by the type of activity. Men were more likely to view activities as safe compared with women, similar to findings elsewhere. ${ }^{14}$ Individuals with higher income were more likely to view activities as safe, perhaps a result of facing fewer barriers to physical distancing. ${ }^{15}$ This could also reflect wealth differentials in the experience of the pandemic at this point of time, with increased COVID-19 transmission and case volumes in low-income and minority populations. ${ }^{16}$ There were few differences by education. Nearly universally, Democrats and independents were more likely than Republicans to view activities as unsafe, potentially a reflection of the highly polarised US climate in which information about COVID-19 has been influenced by politics.

Previous studies about perceived health and economic risks associated with COVID-19 have shown significant differences in risk perception by age, gender, education and other sociodemographic factors. A cross-sectional survey of US adults conducted in March 2020 found lower risk perceptions but higher prevalence of social distancing behaviours, among older adults. ${ }^{17}$ Other studies have shown mixed results by age, with some reporting higher risk perceptions for older adults ${ }^{18}$ and others lower ${ }^{19}$ Our study showed that older respondents were more likely to view social gatherings with many people and indoor activities as unsafe and more likely to view activities such as going to the grocery store, participating in outdoor activities, visiting elderly relatives and visiting the doctor or emergency room as safe.

Studies have found lower perceived risk of COVID-19 infection and mortality among black/African-American persons. ${ }^{17}$ Another study reported higher risk perceptions concerning COVID-19 in Native American/Alaska Native and Asian groups relative to black/African-American persons. ${ }^{18}$ A large cross-sectional national US sample showed that Hispanic and first-generation immigrants had significantly higher risk perceptions of COVID-19 infection and death than other groups, and anxiety, discrimination and selecting to take the survey in Spanish were related to perceived risk. ${ }^{20}$ Associations between respondent race/ethnicity and risk perceptions in our study varied by activity; for some, such as attending gatherings, visiting grocery stores and attending church, there were no significant differences between groups. However, black/African-American and, especially, Hispanic/Latino respondents were more likely to view several activities, such as dining and visiting friends outdoor, as unsafe compared with white/Caucasian respondents. Evidence suggests that black and Hispanic groups have had higher rates of infection and mortality from COVID-19. ${ }^{21}$ This raises questions as to how structural racism and socioeconomic and health disparities influence access to information and trust in health services and authorities in the context of the COVID-19 pandemic. Authors of a qualitative study in a rural Latino community suggested that risk perceptions and concerns were linked to stress of loss of employment. ${ }^{22}$ Responsibility rests with politicians, 
health authorities and community leaders to communicate evidence-based information in a manner that is honest and clear, easily accessible and culturally appropriate. Respondents in the study of perceptions in the rural Latino community suggested, for example, a personalised approach to delivering information, by using email or text messages from nearby universities, their medical providers or the local health department. ${ }^{922}$

Political affiliation and risk perceptions were among the strongest associations identified our study. Democrats and independents had higher risk perceptions than Republicans for nearly all of the activities assessed. Other studies have documented links between Republican affiliation or conservative ideology and lower risk perceptions of COVID-19 infection. ${ }^{23}$ A recent study of an international cohort of social media users found that COVID-19 risk perception and trust in science mediate the relationship between conservative political ideological and lower compliance with COVID-19 preventive interventions. ${ }^{24}$ Another online study of participants reported that intentions to socially distance tended to be lower among conservatives than liberals, yet those with low trust in science were less likely to support social distancing regardless of ideology; furthermore, messages delivered by conservative public figures were more likely to reduce the ideological social distancing intentions gap. ${ }^{25}$

Examining how sociodemographic factors and other determinants influence risk perceptions can help identify how inequities lead to increased health risks in specific disadvantaged groups. Risk perceptions are complex and intertwined with other constructs-such as understanding of disease and trust in science-and these factors should be considered when determining how risk perceptions are related to preventive behaviours. While some studies have shown close correlation between perceived disease severity and preventive behaviours, others have reported discrepancies between perceived disease risk and adherence to prevention behaviours. A study in China, for example, conducted in May 2020, found that perceived understanding of the disease and preventive interventions can mediate the effect of risk perceptions on social distancing behaviours. ${ }^{26}$ Along with studies linking risk perceptions, trust in science and behaviours, these findings suggest that without understanding how these complicated relationships function, efforts to change risk perceptions alone may be inappropriate and inadequate for affecting behaviour. ${ }^{27} 28$

Early efforts to control the COVID-19 pandemic, prior to widespread availability of vaccines, have been reliant on non-pharmaceutical interventions (ie, social distancing, mask use and lockdowns). A review of educational initiatives to promote such interventions found that their effectiveness is dependent on individual and community willingness to participate and collaborate with local authorities, and key factors, influencing willingness, included ethical, psychological, and practice factors. ${ }^{29}$ Moreover, educational initiatives, communication strategies and timely information sharing at the community level are critical to implementation of these interventions. Messaging approaches that are tailored to their audience and rooted behavioural change theoretical constructs, such as risk perceptions and self-efficacy, may be most effective ${ }^{3031}$ Hence, a nuanced understanding of knowledge, risk perceptions and self-efficacy for different populations, especially disadvantaged groups, is a critical prerequisite to efforts to control spread of disease through behavioural interventions.

Lastly, risk perceptions are likely to vary by location, local COVID-19 incidence and over time as more information becomes available, factors such as "pandemic fatigue' increase in prevalence, and more recent experiences exert a stronger influence on how people view the pandemic. In the USA, many published studies to date were conducted during the early phases of the pandemic and focused on perceived risks of infection or mortality and health behaviours, often without detailed information on race/ethnicity. ${ }^{27} 32$ Our findings supplement this body of evidence by providing insights into perceived risks for specific activities, sufficient sample size to explore associations by race/ethnicity and status of these perceptions during a later stage of the COVID-19 pandemic.

This study had limitations. Selection bias associated with online surveys is well established, for example, underrepresenting individuals who are older, without internet access, have lower income and have less formal education; this effect is difficult to quantify, in either direction or magnitude, and may limit the generalisability of our results. However, the digital divide in internet access has shrunk over time. ${ }^{33}$ Despite our large sample size, samples for strata of important participant characteristics, including certain racial and ethnic minorities, were too small to provide sufficient statistical power for our analyses; still, we had sufficient statistical power to examine racial and ethnic differences between black/AfricanAmerican, Hispanic/Latino and white/Caucasian groups, which very few studies have done. Our questionnaire did not collect data on some characteristics that could affect risk perceptions, including presence of underlying health conditions, type of employment or whether the respondent knew someone who had been infected with COVID19. Future surveys should consider using a larger sample size to allow for examination of racial and ethnic differences with greater statistical power and inclusion of questions about important determinants of risk perceptions, such as chronic health conditions.

\section{CONCLUSION}

Our findings suggest the importance of socioeconomic differences, health disparities and structural racism for efforts to control the COVID-19 pandemic, including preventive behaviours, care seeking for testing and treatment and vaccination strategies. Further research should address how evidence-based interventions and programmes can be tailored in consideration of these 
barriers with a goal of increased health equity in the pandemic response.

\section{Author affiliations}

${ }^{1}$ Department of International Health, Johns Hopkins Bloomberg School of Public Health, Baltimore, Maryland, USA

${ }^{2}$ Department of Epidemiology, Johns Hopkins Bloomberg School of Public Health, Baltimore, Maryland, USA

${ }^{3}$ Department of Medicine, Division of Infectious Diseases, Johns Hopkins University School of Medicine, Baltimore, Maryland, USA

${ }^{4}$ Johns Hopkins University Global mHealth Initiative, Johns Hopkins Bloomberg School of Public Health, Baltimore, Maryland, USA

Acknowledgements We appreciate the team at Dynata for working closely with us during collection of the data. We would also like to recognise the Johns Hopkins University COVID-19 Research Response Fund for their initial support in getting this project off the ground. Thank you also to Dr Gregory Kirk for help in developing the initial project plan. Lastly, thank you to the Johnson \& Johnson Foundation for supporting this research project.

Contributors SHM, SSS, DGG, SA and ABL created the questionnaire and designed the survey. DGG worked with Dynata to collect the data. DJE, AJZ, PB and JE conducted the analysis and drafted the manuscript. All authors contributed to the analysis, interpretation of the results and reviewed and provided inputs to the manuscript. DJE, as guarantor, accepts full responsibility for the work and the conduct of the study, had access to the data, and controlled the decision to publish. All authors meet the ICMJE criteria for authorship.

Funding This research was supported by a grant from the Johnson \& Johnson Foundation (J\&J Grant 90089979) and Johns Hopkins University COVID-19 Research Respond Fund.

Competing interests SHM reports personal fees from Gilead Sciences, outside the submitted work. SSS reports grants/products from Gilead Sciences and grants/ products from Abbott Diagnostics, outside the submitted work.

Patient consent for publication Consent obtained directly from patient(s).

Ethics approval The study received ethical approval from the Institutional Review Board at Johns Hopkins Bloomberg School of Public Health, Baltimore, USA (IRB00012413). Participants gave informed consent to participate in the study before taking part.

Provenance and peer review Not commissioned; externally peer reviewed.

Data availability statement Data are available on reasonable request. Data can be made available on reasonable request.

Supplemental material This content has been supplied by the author(s). It has not been vetted by BMJ Publishing Group Limited (BMJ) and may not have been peer-reviewed. Any opinions or recommendations discussed are solely those of the author(s) and are not endorsed by BMJ. BMJ disclaims all liability and responsibility arising from any reliance placed on the content. Where the content includes any translated material, BMJ does not warrant the accuracy and reliability of the translations (including but not limited to local regulations, clinical guidelines, terminology, drug names and drug dosages), and is not responsible for any error and/or omissions arising from translation and adaptation or otherwise.

Open access This is an open access article distributed in accordance with the Creative Commons Attribution Non Commercial (CC BY-NC 4.0) license, which permits others to distribute, remix, adapt, build upon this work non-commercially, and license their derivative works on different terms, provided the original work is properly cited, appropriate credit is given, any changes made indicated, and the use is non-commercial. See: http://creativecommons.org/licenses/by-nc/4.0/.

ORCID iD

Daniel J Erchick http://orcid.org/0000-0002-2852-280X

\section{REFERENCES}

1 Center for Systems Science and Engineering (CSSE) at Johns Hopkins University (JHU). COVID-19 Dashboard. Johns Hopkins University, 2020.

2 Millett GA, Jones AT, Benkeser D, et al. Assessing differential impacts of COVID-19 on black communities. Ann Epidemiol 2020;47:37-44.
3 Muñoz-Price LS, Nattinger AB, Rivera F, et al. Racial disparities in incidence and outcomes among patients with COVID-19. JAMA Netw Open 2020;3:e2021892.

4 Alcendor DJ. Racial Disparities-Associated COVID-19 mortality among minority populations in the US. J Clin Med 2020;9. doi:10.3390/jcm9082442. [Epub ahead of print: 3007 2020].

5 Dong E, Du H, Gardner L. An interactive web-based dashboard to track COVID-19 in real time. Lancet Infect Dis 2020;20:533-4.

6 Zheng Q, Jones FK, Leavitt SV, et al. HIT-COVID, a global database tracking public health interventions to COVID-19. Sci Data 2020;7:286.

7 Mantwill S, Monestel-Umaña S, Schulz PJ. The relationship between health literacy and health disparities: a systematic review. PLoS One 2015;10:e0145455.

8 Poletti P, Ajelli M, Merler S. The effect of risk perception on the 2009 H1N1 pandemic influenza dynamics. PLoS One 2011;6:e16460-e.

9 Bavel JJV, Baicker K, Boggio PS, et al. Using social and behavioural science to support COVID-19 pandemic response. Nat Hum Behav 2020;4:460-71.

10 Rosenstock IM. The health belief model and preventive health behavior. Health Educ Monogr 1974;2:354-86.

11 Ferrer R, Klein WM. Risk perceptions and health behavior. Curr Opin Psychol 2015;5:85-9.

12 Clipman SJ, Wesolowski AP, Gibson DG, et al. Rapid real-time tracking of non-pharmaceutical interventions and their association with SARS-CoV-2 positivity: the COVID-19 pandemic pulse study. medRxiv 2020. doi:10.1101/2020.07.29.20164665. [Epub ahead of print: 11 Aug 2020].

13 World Health Organization. Transmission of SARS-CoV-2: implications for infection prevention precautions: scientific brief. World Health Organization, 2020.

14 Galasso V, Pons V, Profeta P, et al. Gender differences in COVID-19 attitudes and behavior: panel evidence from eight countries. Proc Natl Acad Sci U S A 2020;117:27285-91.

15 Jay J, Bor J, Nsoesie EO, et al. Neighbourhood income and physical distancing during the COVID-19 pandemic in the United States. Nat Hum Behav 2020;4:1294-302.

16 Adhikari S, Pantaleo NP, Feldman JM, et al. Assessment of community-level disparities in coronavirus disease 2019 (COVID-19) infections and deaths in large US metropolitan areas. JAMA Netw Open 2020;3:e2016938.

17 Masters NB, Shih S-F, Bukoff A, et al. Social distancing in response to the novel coronavirus (COVID-19) in the United States. PLoS One 2020;15:e0239025.

18 Malik AA, McFadden SM, Elharake JA. COVID-19 risk perception among U.S. adults: changes from February to may 2020. medRxiv 2020:2020.08.20.20178822.

19 Bordalo P, Coffman K, Gennaioli N. Older people are less pessimistic about the health risks of Covid-19 (Report No.: w27494). Cambridge, MA: National Bureau of Economic Research, 2020.

20 Jamieson T, Caldwell D, Gomez-Aguinaga B, et al. Race, ethnicity, Nativity and perceptions of health risk during the COVID-19 pandemic in the US. Int J Environ Res Public Health 2021;18:11113.

21 Gold JAW, Rossen LM, Ahmad FB, et al. Race, Ethnicity, and Age Trends in Persons Who Died from COVID-19 - United States, MayAugust 2020. MMWR Morb Mortal Wkly Rep 2020;69:1517-21.

22 Moyce S, Velazquez M, Claudio D, et al. Exploring a rural Latino community's perception of the COVID-19 pandemic. Ethn Health 2021;26:126-38.

23 Barrios JM, Hochberg YV. Risk perceptions and politics: evidence from the COVID-19 pandemic. J financ econ 2021;142:862-79.

24 Plohl N, Musil B. Modeling compliance with COVID-19 prevention guidelines: the critical role of trust in science. Psychol Health Med 2021;26:1-12.

25 Koetke J, Schumann K, Porter T. Trust in science increases conservative support for social distancing. Group Processes \& Intergroup Relations 2021;24:680-97.

26 Xie K, Liang B, Dulebenets MA, et al. The impact of risk perception on social distancing during the COVID-19 pandemic in China. Int $J$ Environ Res Public Health 2020;17:6256.

27 Berg MB, Lin L. Prevalence and predictors of early COVID-19 behavioral intentions in the United States. Trans/ Behav Med 2020;10:843-9.

28 Smith LE, Potts HWW, Amlot R. Adherence to the test, trace and isolate system: results from a time series of 21 nationally representative surveys in the UK (the COVID-19 Rapid Survey of Adherence to Interventions and Responses [CORSAIR] study). medRxiv 2020:2020.09.15.20191957.

29 Khorram-Manesh A, Dulebenets MA, Goniewicz K. Implementing public health Strategies-The need for educational initiatives: a systematic review. Int J Environ Res Public Health 2021;18:5888. 
30 Latimer AE, Brawley LR, Bassett RL. A systematic review of three approaches for constructing physical activity messages: what messages work and what improvements are needed? Int J Behav Nutr Phys Act 2010;7:36.

31 Limaye RJ, Holroyd TA, Blunt M, et al. Social media strategies to affect vaccine acceptance: a systematic literature review. Expert Rev Vaccines 2021;20:959-73.
32 Canning D, Karra M, Dayalu R, et al. The association between age, COVID-19 symptoms, and social distancing behavior in the United States. medRxiv 2020:2020.04.19.20065219.

33 Pew Research Center. Internet/Broadband fact sheet, 2019. Available: https://www.pewresearch.org/internet/fact-sheet/internet-broadband/ 